\title{
Bei Erkrankungen der Mundschleimhaut
}

Entzündungen am Zahnfleischsaum, Schwellungen der Mundschleimhaut, schmerzhafte Bläschen: Solche oder ähnliche Probleme im Mundraum sieht Dr. Martin Burkhart in seiner Zahnarztpraxis in Friedrichsdorf im Taunus täglich. Seine Medikationsempfehlung: Ein traditionelles pflanzliches Arzneimittel aus Extrakten der Echten Kamille und Schafgarbe wirksam und verträglich.

Burkhart berichtet „Es gibt offizielle Beschreibungen, welche die Wirkung der Kamille belegen. Auch die Kommission E des Bundesinstituts für Arzneimittel und Medizinprodukte empfiehlt die Anwen-

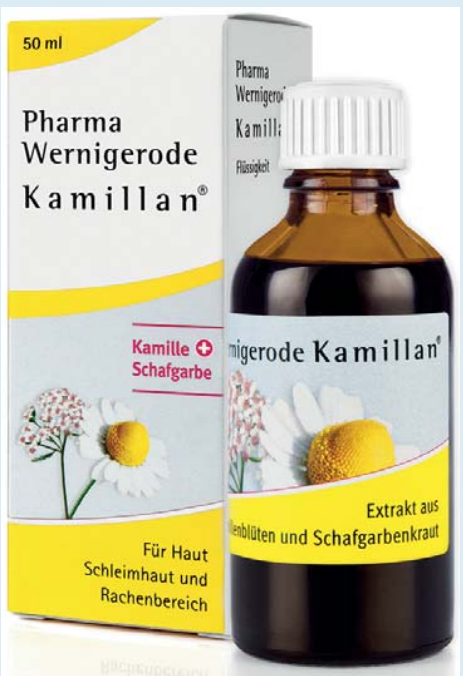

dung von Kamillenblüten-Extrakten äußerlich bei Haut- und Schleimhautentzündungen. Ich verordne meinen Patienten, die Probleme mit der Mundschleimhaut haben, ein zugelassenes Arzneimittel mit Kamille und Schafgarbe - und zwar aufs Grüne Rezept. So kann ich sicher sein, dass der Patient auch das richtige Präparat in der Apotheke bekommt: Pharma Wernigerode Kamillan“. Das aus der als Blutstillkraut bekannten, bitteren Heilpflanze Schafgarbe gewonnene ätherische Öl ist dem der Kamille verwandt und hat ebenfalls antibakterielle und wundheilungsfördernde Eigenschaften. Zusätzlich besitzen die enthaltenen Gerbstoffe adstringierende Effekte. 